\title{
Influence of Supplementing Pasture-Based Primiparous Holstein- Friesian Dairy Cows with Crude Degummed Canola Oil on Milk Fatty Acid Composition
}

\author{
John Roger Otto ${ }^{1}$, Bunmi Sherifat Malau-Aduli ${ }^{2}$, Peter David Nichols ${ }^{3}$ and \\ Aduli Enoch Othniel Malau-Aduli ${ }^{1,4, *}$
}

${ }^{1}$ Animal Science and Genetics, Tasmanian Institute of Agriculture, School of Land and Food, Faculty of Science, Engineering and Technology, University of Tasmania, Private Bag 54 Hobart, TAS 7001, Australia

${ }^{2}$ School of Medicine and Dentistry, Faculty of Medicine, Health and Molecular Sciences, James Cook University, Townsville, QLD 4811, Australia

${ }^{3}$ CSIRO Food Futures Flagship, Division of Marine and Atmospheric Research, G.P.O. Box 1538, Hobart, TAS 7001, Australia

${ }^{4}$ School of Veterinary and Biomedical Sciences, Faculty of Medicine, Health and Molecular Sciences, James Cook University, Townsville, QLD 4811, Australia

\begin{abstract}
The quest for alternative sources of healthy nutrients that facilitate the modification of milk without compromising drinking quality is a continuous research endeavour. The objective of the study was to quantify the milk fatty acid composition of pasture-based primiparous Holstein-Friesian dairy cows supplemented with crude degummed canola oil (CDCO) with a view to improving the milk quality for beneficial health effects. This study tested the hypothesis that incremental supplementation of grazing primiparous Holstein-Friesian cows with CDCO will alter milk fatty acid composition towards increased total monounsaturates. Comparisons were made between unsupplemented grazing dairy cows and their peers on dietary supplements containing low $(25 \mathrm{ml} / \mathrm{Kg} \mathrm{DM})$, medium $(35 \mathrm{ml} / \mathrm{Kg} \mathrm{DM})$ or high levels $(50 \mathrm{ml} / \mathrm{kg} \mathrm{DM})$ of CDCO in addition to ad libitum grazing access to pasture. There was no significant effect $(p>0.05)$ of CDCO supplementation for eight weeks on the proportions of total polyunsaturated fatty acids (tPUFA), omega-3 ( $\omega-3$ ) and omega-6 $(\omega-6)$ fatty acids in milk. However, significant impacts of CDCO were observed on the proportions of

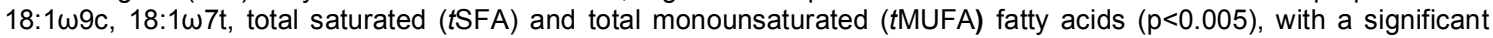
increase in the MUFA/SFA ratio in cows consuming CDCO. It was concluded that incremental levels of CDCO supplementation can modify the fatty acid composition of milk towards increased monounsaturates without any negative impact on grazing primiparous cows.
\end{abstract}

Keywords: Monounsaturated Fatty Acids, Polyunsaturated Fatty Acids, Saturated Fatty Acids, omega-3, omega-6.

\section{INTRODUCTION}

The demand for milk and other dairy products has slightly increased in Australia, with the consumption of drinking milk per capita rising from 104.4 liters in $2010 / 11$ to 106.2 liters in 2011/12, respectively [1]. The primary focus of dairy farmers is to increase milk production with adequate fat and protein compositions because of the associated economic benefits of milk solids. In response to health concerns about coronary heart disease, obesity and arteriosclerosis, research interests in modifying milk fatty acid composition toward less saturated medium-chain $(\leq \mathrm{C} 12)$ fatty acids and more long-chain $(\geq \mathrm{C} 18)$ polyunsaturated fatty acids (PUFA) are on the increase. The simplest way of altering milk fat composition is to supplement the diets

*Address correspondence to this author at Animal Science and Genetics, Tasmanian Institute of Agriculture, School of Land and Food, Faculty of Science, Engineering and Technology, University of Tasmania, Private Bag 54 Hobart, TAS 7001, Australia; School of Veterinary and Biomedical Sciences, Faculty of Medicine, Health and Molecular Sciences, James Cook University, Townsville, QLD 4811, Australia; Tel: +61-3-6226-2717; Fax: +61-3-62267444; E-mail: aduli.malauaduli@utas.edu.au; aduli.malauaduli@jcu.edu.au of cows with unsaturated lipids [2,3]. Milk fat composition is changed more by the amount and composition of dietary fat than any other dietary component, and several studies [4-6] have been published on the response of milk fat composition to dietary lipid supplements in dairy cows. However, in Tasmania's pasture-based dairy production system, dietary supplementation of lactating cows with fat is not a common nutritional management practice, mainly because of its unknown impacts on milk fatty acid composition and other lactation traits. Previous fat studies in other dairy systems have reported the effects of fat supplements on milk fatty acid profiles $[2,3,6]$. Dietary fat supplementation of dairy cows in pasturebased production systems has been targeted toward enhancing the proportions of $\omega-3$ and $\omega-6$ fatty acids at the expense of SFA to achieve desirable human health benefits [7-9]. However, the beneficial health effect of fat supplements can be countered by the concurrent production of trans-monounsaturated fatty acids (MUFA) known to be associated with cholesterol [10, 11]. However, published studies in Australia 
investigating the impact of dietary fat supplementation using crude degummed canola oil (CDCO) on milk fatty acid profiles of pasture-based primiparous cows are at best, scanty or non-existent, hence the need for this study to fill in the knowledge gap.

Canola oil products are readily available in Australia, and represent an excellent source of dietary fat, especially oleic acid $[12,13]$. However, extensive rumen biohydrogenation of canola can lead to the formation of trans-MUFA, an intermediate carbon-chain group of fatty acids [14]. Therefore, robust knowledge is required about the impact of supplementing lactating cows with CDCO on milk fatty acid composition. Furthermore, contrasting reports on the effect of canola supplementation on milk fatty acids abound in the published literature, but there is a dearth of rigorously peered reviewed information on the use of CDCO as a supplement in pasture-based dairy production systems. However, studies conducted elsewhere using soybean and linseed oil reported an increase in the proportion of PUFA (C18:2 cis-9,12 and C18:3 cis-9,12,15), whereas feeding cows with rapeseed oil decreased the proportion of MUFA (C18:1 cis-9) in milk fat [15]. Therefore in achieving this paper's objective, it was hypothesized that incremental supplementation of grazing primiparous Holstein-Friesian cows with CDCO will alter milk fatty acid composition towards increased total monounsaturates.

\section{MATERIALS AND METHODS}

All experimental procedures were in accordance with the University of Tasmania (UTAS) Animal Ethics Committee guidelines, the 1993 Tasmania Animal Welfare Act and the 2004 Australian Code of Practice for the Care and Use of Animals for Scientific Purposes.

\section{Site and Climatic Conditions}

The experiment was carried out in spring from September to November 2012 at the Dairy Research Centre of the Tasmanian Institute of Agriculture in Somerset, North-West of Tasmania, Australia, when the annual rainfall and humidity were approximately $2500 \mathrm{~mm}$ and $60 \%$, respectively. Tasmania is Australia's smallest state with a land size of 68,000 square kilometres and located within the cool, temperate, climatic zone at latitude $42^{\circ}$ South and longitude $147^{\circ}$ East characterized by four distinct seasons (winter, autumn, spring and summer).

\section{Animals and Treatments}

Body condition score (BCS) of the cows was visually assessed on a scale of 1 to $8[16,17]$. A total of 20 primiparous, spring-calving, and purebred Holstein-Friesian cows (average live-weight of $400 \pm 40$ $\mathrm{Kg}, \mathrm{BCS} 4 \pm 1$ and $40 \pm 8$ DIM) were randomly allocated into 1 of 4 treatments of CDCO $(25 \mathrm{ml} / \mathrm{Kg}$ $\mathrm{DM}, 35 \mathrm{ml} / \mathrm{Kg} \mathrm{DM}$ and $50 \mathrm{ml} / \mathrm{Kg} \mathrm{DM}$ ) and the control (no CDCO $0 \mathrm{ml} / \mathrm{Kg} \mathrm{DM})$. All experimental cows $(n=5$ per treatment group) were placed under the same grazing management and rotated in electric-fenced paddocks. The Control group of cows were offered wheat-based pellets with no CDCO and grazed on the same pastures comprising a mixture of ryegrass (Lolium perenne), cocksfoot (Dactylis glomerata), and white clover (Trifolium repens). Water was offered ad libitum. Cows in all the other treatment groups also grazed the same pastures as the Control treatment cows but were offered CDCO plus wheat-based pellets at the rate of $50 \mathrm{ml} / \mathrm{Kg}$ DM (High), $35 \mathrm{ml} / \mathrm{Kg}$ DM (Medium) and $25 \mathrm{ml} / \mathrm{Kg}$ DM (Low) level of supplementation. The current level of CDCO was based on $7 \%$ total fat in the diet of grazing cows [18]. Supplements were offered to cows in two splits of $3 \mathrm{~kg}$ each during morning and evening milking sessions at 05:00 $\mathrm{h}$ and 15:00 $\mathrm{h}$, respectively, hence each cow received $6 \mathrm{~kg}$ of the pelleted supplement daily for eight weeks after two weeks of adjustment. There were no left-over feed residuals from any of the group of cows. The chemical and fatty acid compositions of the treatment, control and basal feeds are presented in Tables 1 and 2.

\section{Feed Chemical Composition and Analysis}

Dry matter (DM) content of the basal and experimental diets was determined by drying the samples to a constant temperature at $65^{\circ} \mathrm{C}$ in a fanforced oven, finely ground to pass through a $2 \mathrm{~mm}$ sieve using a Laboratory Mill (Thomas Model 4 Wiley® Mill; Thomas Scientific), and further drying at $105^{\circ} \mathrm{C}$ for $24 \mathrm{~h}$. The DM was computed as the difference between the initial and final weights of the samples. Ash content was determined by combusting the samples in a furnace at $600^{\circ} \mathrm{C}$ for 8 hours. Neutral detergent (NDF) and acid detergent (ADF) fiber contents were measured using an Ankom fiber analyzer ANKOM220; ANKOM Technology, USA. [19]. Total nitrogen was determined using a Thermo Finnigan EA 1112 Series Flash Elemental Analyzer [20] and the values multiplied 
Table 1: Chemical Composition of Experimental and Basal Feeds

\begin{tabular}{|c|c|c|c|c|}
\hline \multirow{2}{*}{$\begin{array}{l}{ }^{\mathrm{c}} \text { Chemical } \\
\text { composition }\end{array}$} & \multicolumn{3}{|c|}{${ }^{\mathrm{a}}$ Feed components } & \multirow[t]{2}{*}{ bunits } \\
\hline & $\begin{array}{l}\text { Treatment Feed (high canola } \\
\text { oil) }\end{array}$ & $\begin{array}{l}\text { Control Feed (No } \\
\text { canola oil) }\end{array}$ & $\begin{array}{c}\text { Basal Feed } \\
\text { (Pasture) }\end{array}$ & \\
\hline$M C$ & 8.2 & 9.1 & 55.0 & $\mathrm{~g} / 100 \mathrm{~g} \mathrm{DM}$ \\
\hline DM & 91.8 & 90.9 & 94.5 & $g / 100 g$ DM \\
\hline ADF & 8.0 & 9.0 & 27.7 & $\mathrm{~g} / 100 \mathrm{~g} \mathrm{DM}$ \\
\hline NDF & 20.0 & 21.1 & 45.9 & $\mathrm{~g} / 100 \mathrm{~g} \mathrm{DM}$ \\
\hline EE & 6.2 & 2.1 & 3.0 & $\mathrm{~g} / 100 \mathrm{~g} \mathrm{DM}$ \\
\hline Ash & 9.7 & 8.9 & 9.3 & $\mathrm{~g} / 100 \mathrm{~g} \mathrm{DM}$ \\
\hline NFC & 52.8 & 59.0 & 23.9 & $\mathrm{~g} / 100 \mathrm{~g} \mathrm{DM}$ \\
\hline $\mathrm{CP}$ & 12.7 & 10.4 & 21.0 & $\mathrm{~g} / 100 \mathrm{~g} \mathrm{DM}$ \\
\hline ME & 4083.3 & 4065.7 & 3999.2 & $\mathrm{~kJ} / 100 \mathrm{~g} \mathrm{DM}$ \\
\hline
\end{tabular}

${ }^{a-b}$ All feeds were analyzed based on a dry weight basis; ${ }^{c}$ Moisture content (MC), Dry matter (DM), organic matter (OM), neutral detergent fiber (NDF), acid detergent fiber (ADF), non-fibrous carbohydrate (NFC), ether extract (EE), crude protein (CP) and metabolisable energy (ME).

by 6.25 to give the crude protein (CP) percentage. Ether extract (EE) was determined using an Ankom fat/oil extractor $\left(\right.$ ANKOM $^{\mathrm{XT15}}$; ANKOM Technology, USA). Metabolisable energy (ME) was calculated as per Weiss [21].

\section{Milk Sample Collection}

Weekly milk samples were bulked from daily consecutive milkings at 05:00h and 15:00h for 8 weeks $(2,240$ samples in total). Representative aliquots of fresh milk samples from each cow were collected using the Milking Point Controller (MPC 680) fitted to the De Laval herringbone milking machine into labelled plastic vials containing bronopol blue milk preservative and stored at $-20^{\circ} \mathrm{C}$ until further analysis [22]. No experimental cow suffered mastitis before, during or after the feeding trial period.

\section{Milk Fatty Acid Analysis}

The milk samples were analysed using the GLC method applied by the Commonwealth Scientific and Industrial Research Organization (CSIRO) Food Futures Flagship's Omega-3 Research Group, Marine and Atmospheric Research, Hobart, Tasmania, Australia, following direct methylation according to International Organization for Standardization (ISO) procedures. The procedure was as follows: Approximately $0.5 \mathrm{~g}$ of milk was freeze-dried and $0.05 \mathrm{mg}$ of feed samples were weighed in duplicates into clean, $10 \mathrm{ml}$ screw-top methylation tubes and a freshly made solution of trans-esterification reaction mix (methanol:hydrochloric acid:chloroform (10:1:1 $\mathrm{v} / \mathrm{v} / \mathrm{v}, 3 \mathrm{ml}$ ) was added. Aliquots of milk were suspended in the trans-esterification solution and vortexed before trans-esterification at $80^{\circ} \mathrm{C}$ for two hours. Each test tube was cooled for five minutes before $1 \mathrm{ml}$ of MilliQ water was added and the fatty acid methyl esters (FAME) were extracted using $3 \times 2 \mathrm{ml}$ of hexane:dichloromethane at a ratio of $4: 1 \mathrm{v} / \mathrm{v}$. Extracts from the methylation tubes were pipetted into vials, diluted with a known concentration of 19:0 FAME contained in chloroform as the internal injection standard and were ready for gas chromatographic analysis. Chloroform was added to two vial tubes to form the blank controls for milk and feed samples. An Agilent Technologies $7890 \mathrm{~B}$ GC equipped with a $15 \mathrm{~m} \mathrm{x}$ $0.11 \mathrm{~mm}$ internal diameter cross-linked Equity-1 (0.1um film thickness) fused-silica capillary column, a split/splitless injector, a 7683B series autosampler and flame ionization detector [23] was used to analyze the FAME. Quantification of recorded peak areas was carried out using the software package Agilent Technologies Chemstation (Palo Alto, CA, USA). FAME identity was confirmed by a GCQ (Thermoquest, USA) GC-mass spectrometer (GC-MS)', fitted with an on-column injector and an HP-5 cross-linked methyl silicone fused silica capillary column $(50 \mathrm{~m} \times 0.32 \mathrm{~mm}$ i.d.) of similar polarity to that described above. Quantification of recorded peak areas was carried out using the software package Millennium 32 v3.05.01 (Waters Corporation, USA). FAME identity was confirmed by an MD 800 (Fissions, UK) or GCQ (Thermoquest, USA) GC-mass spectrometers (GCMS) [23]. Quantified peaks were exported into an excel file, converted to total fatty acid percentages and subjected to statistical analysis.

\section{Statistical Analysis}

Initially, summary statistics by level and week of supplementation were computed to obtain means, standard deviations, standard error, minimum and 
Table 2: Fatty Acids (\% of Total Fatty Acids) in Basal and Experimental Feeds

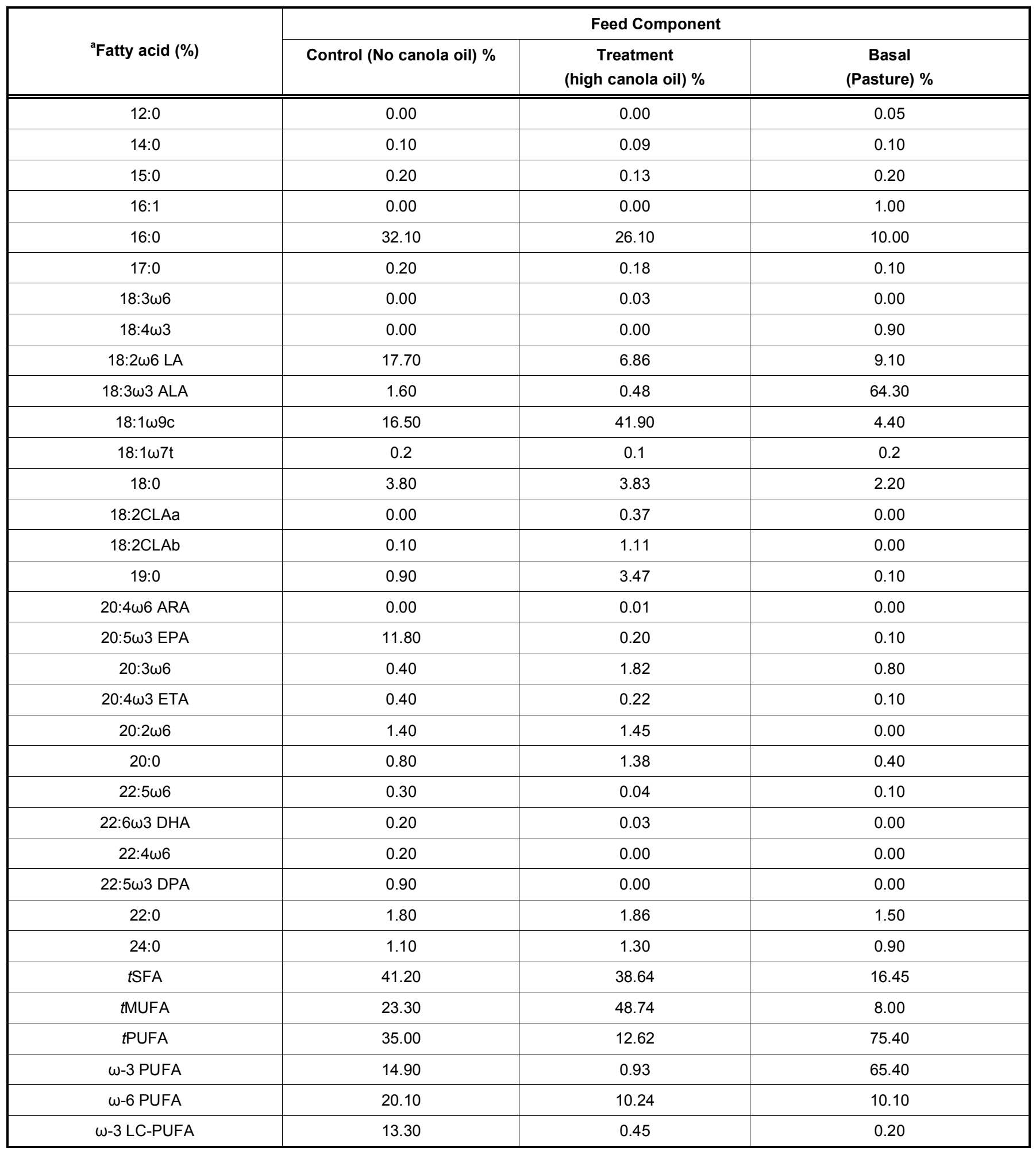

${ }^{a} \sum t S F A$ is the sum of $12: 0,13: 0$, i14:0,14:0, i15:0, a15:0,15:0, i16:0, 16:0, i17:0, 17:0, i18:0, 18:0, 19:0, 20:0, 20:0, 22:0, 24:0; $\sum$ tMUFA is the sum of 14:1 $\omega-5 c$

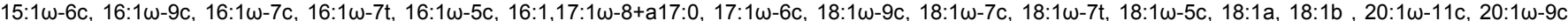

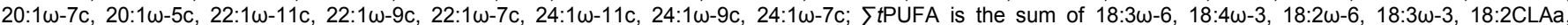

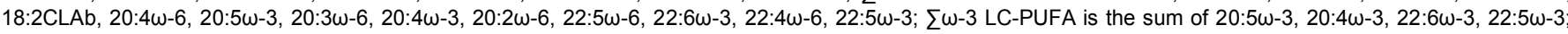
$\sum \omega-3$ PUFA is the sum of $18: 4 \omega-3,18: 3 n-3,20: 4 \omega-3,20: 5 \omega-3,22: 6 \omega-3,22: 5 \omega-3 ; \sum \omega-6$ is the sum of $15: 1 \omega-6,17: 1 \omega-6,18: 2 \omega-6,18: 3 \omega-6,20: 4 \omega-6,20: 3 \omega-6,20: 2 \omega-$ $6,22: 5 \omega-6,22: 4 \omega-6 . t S F A=$ total saturated fatty acids, tMUFA= total monounsaturated fatty acids, tPUFA= total polyunsaturated fatty acids, $\omega-3 \mathrm{FA}=$ total omega- 3 fatty acids, $\omega-6$ FA=total omega- 6 fatty acids, $\omega-3$ LC-FA=total omega-3 long chain fatty acids. 
Table 3: Mean Fatty Acid Concentration ( $\mathbf{S E}$ ) (\% Total FA) of Milk Samples by Level of Supplementation with CDCO

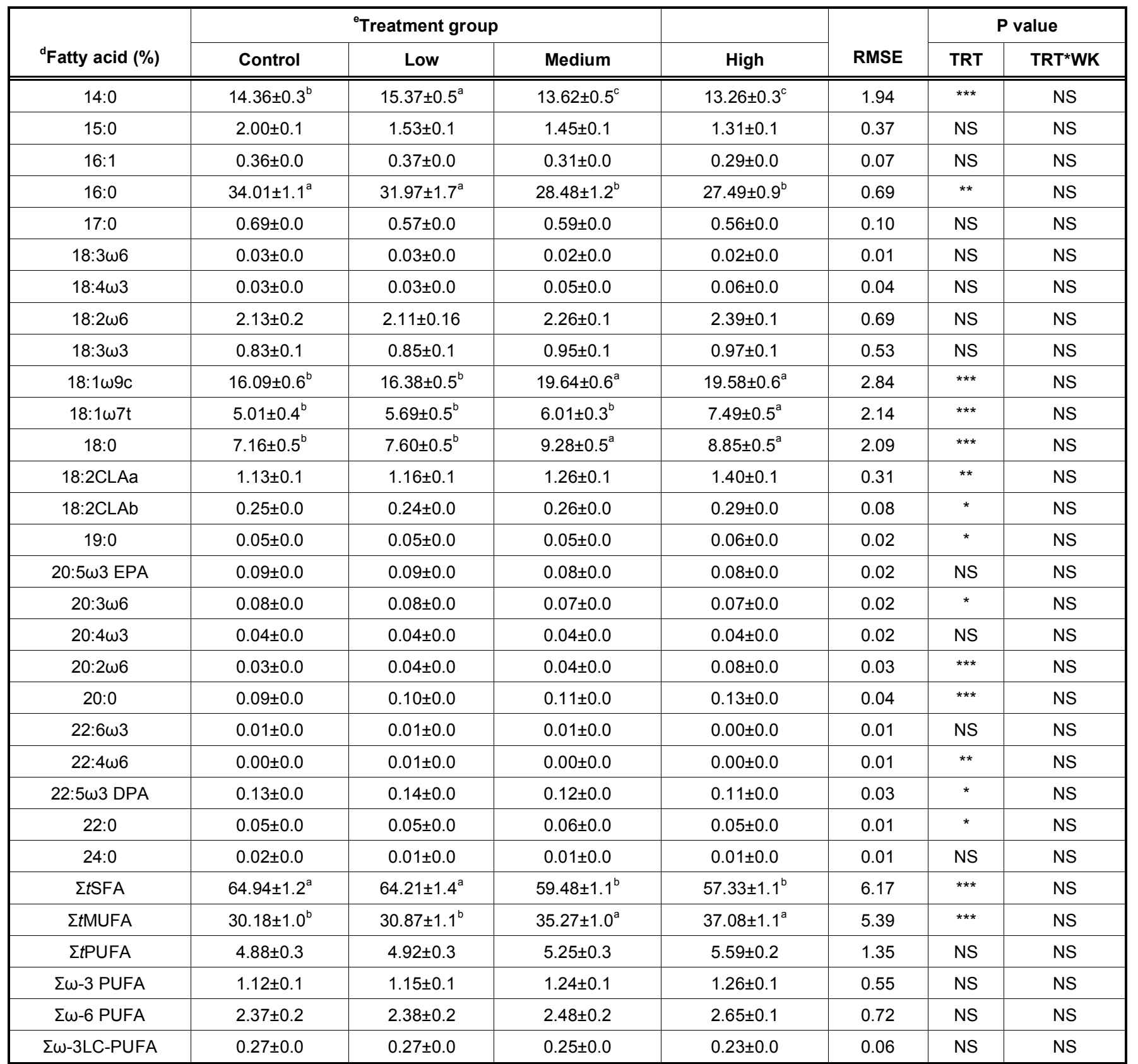

${ }^{a-c}$ Values with different superscript are significantly different; ${ }^{\mathrm{d}} \sum$ tSFA is the sum of 12:0, 13:0, i14:0,14:0, i15:0, a15:0,15:0, i16:0, 16:0, i17:0, 17:0, i18:0, 18:0, 19:0,

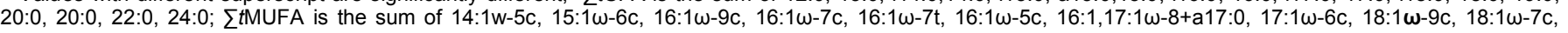
$18: 1 \omega-7 t, 18: 1 \omega-5 c, 18: 1 a, 18: 1 b, 20: 1 \omega-11 c, 20: 1 \omega-9 c, 20: 1 \omega-7 c, 20: 1 \omega-5 c, 22: 1 \omega-11 c, 22: 1 \omega-9 c, 22: 1 \omega-7 c, 24: 1 \omega-11 c, 24: 1 \omega-9 c, 24: 1 \omega-7 c ; ~ \sum t P U F A$ is the sum

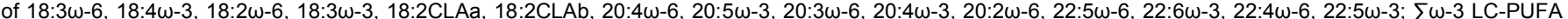
is the sum of $20: 5 \omega-3,20: 4 \omega-3,22: 6 \omega-3,22: 5 \omega-3 ; \sum \omega-3$ PUFA is the sum of $18: 4 \omega-3,18: 3 n-3,20: 4 \omega-3,20: 5 \omega-3,22: 6 \omega-3,22: 5 \omega-3 ; \sum \omega-6$ is the sum of $15: 1 \omega-6$, $17: 1 \omega-6,18: 2 \omega-6,18: 3 \omega-6,20: 4 \omega-6,20: 3 \omega-6,20: 2 \omega-6,22: 5 \omega-6,22: 4 \omega-6 ; t S F A=$ total saturated fatty acids; $t$ MUFA $=$ total monounsaturated fatty acids; $t P U F A=$ total polyunsaturated fatty acids; $\omega-3 \mathrm{FA}=$ total omega-3 fatty acids; $\omega-6 \mathrm{FA}=$ total omega- 6 fatty acids; $\omega-3$ LC-FA=total omega-3 long chain fatty acids; $\mathrm{NS}=$ no significance; ${ }^{*}=$ significant $(P<0.05) ;{ }^{* *}=$ highly significant $(P<0.01) ;{ }^{* * *}=$ very highly significant $(P<0.001) ;{ }^{\mathrm{e}}$ Treatment group= group of cows receiving canola oil;; TRT=treatment feed, WK= Week, RMSE = root mean square error.

maximum values which were closely scrutinised for any data entry errors. Subsequently, milk fatty acid composition was analyzed by repeated measures analysis of variance (PROC MIXED) in SAS [24] in which treatment, week of lactation and week of lactation by treatment interactions were fitted as fixed effects and cow, baseline milk values as random effects. Prior to that, compound symmetry covariance structure, linear, quadratic and cubic contrasts were tested in regression analysis and found to have negligible impacts. Separation between means was conducted using Tukey's pairwise comparison and $\mathrm{P}<0.05$ set as the threshold for significance. 
Table 4: Mean Fatty Acid Concentration ( \pm SE) (\% Total FA) of Milk Samples by Week of Supplementation with CDCO

\begin{tabular}{|c|c|c|c|c|c|c|c|c|c|}
\hline \multirow[b]{2}{*}{${ }^{d}$ Fatty acid (\%) } & \multicolumn{6}{|c|}{${ }^{\mathrm{e}}$ Week of supplementation } & \multirow[b]{2}{*}{ RMSE } & \multicolumn{2}{|c|}{$P$ values } \\
\hline & 0 & 2 & 4 & 6 & 7 & 8 & & WK & TRT*WK \\
\hline $14: 0$ & $12.45 \pm 0.3$ & $14.19 \pm 0.3$ & $14.03 \pm 0.4$ & $15.67 \pm 0.6$ & $13.77 \pm 0.5$ & $14.80 \pm 0.6$ & 1.94 & NS & NS \\
\hline $16: 1$ & $0.25 \pm 0.0$ & $0.35 \pm 0.0$ & $0.36 \pm 0.0$ & $0.33 \pm 0.0$ & $0.35 \pm 0.0$ & $0.35 \pm 0.0$ & 0.07 & NS & NS \\
\hline $16: 0$ & $26.88 \pm 0.8$ & $28.72 \pm 1.0$ & $29.54 \pm 1.4$ & $31.76 \pm 2.3$ & $32.23 \pm 1.4$ & $33.79 \pm 2.2$ & 0.69 & NS & NS \\
\hline $18: 4 \omega 3$ & $0.02 \pm 0.0$ & $0.05 \pm 0.0$ & $0.03 \pm 0.0$ & $0.03 \pm 0.0$ & $0.05 \pm 0.0$ & $0.05 \pm 0.0$ & 0.04 & NS & NS \\
\hline $18: 2 \omega 6$ & $2.58 \pm 0.1^{\mathrm{a}}$ & $2.59 \pm 0.1^{\mathrm{a}}$ & $2.73 \pm 0.2^{\mathrm{a}}$ & $2.08 \pm 0.2^{b}$ & $1.94 \pm 0.2^{b}$ & $1.41 \pm 0.2^{c}$ & 0.69 & $* * *$ & NS \\
\hline $18: 3 \omega 3$ & $1.11 \pm 0.0^{\mathrm{a}}$ & $1.22 \pm 0.1^{\mathrm{a}}$ & $1.10 \pm 0.1^{\mathrm{a}}$ & $0.91 \pm 0.1^{\mathrm{ab}}$ & $0.74 \pm 0.1^{\mathrm{b}}$ & $0.32 \pm 0.1^{\mathrm{c}}$ & 0.53 & $* * *$ & NS \\
\hline $18: 1 \omega 9 c$ & $19.92 \pm 0.5^{\mathrm{a}}$ & $16.41 \pm 0.5^{\mathrm{bc}}$ & $17.35 \pm 0.7^{b c}$ & $16.82 \pm 0.9^{b c}$ & $18.41 \pm 0.8^{\mathrm{ab}}$ & $18.63 \pm 1.0^{\mathrm{ab}}$ & 2.84 & ** & NS \\
\hline $18: 1 \omega 7 t$ & $6.55 \pm 0.5^{\mathrm{ab}}$ & $7.76 \pm 0.6^{a}$ & $6.70 \pm 0.6^{\mathrm{ab}}$ & $5.35 \pm 0.5^{\mathrm{bc}}$ & $5.55 \pm 0.5^{\mathrm{bc}}$ & $4.39 \pm 0.4^{c}$ & 2.14 & $* * *$ & NS \\
\hline 19:0 & $0.06 \pm 0.0$ & $0.05 \pm 0.0$ & $0.05 \pm 0.0$ & $0.05 \pm 0.0$ & $0.04 \pm 0.0$ & $0.05 \pm 0.0$ & 0.02 & NS & NS \\
\hline $20: 5 \omega 3$ EPA & $0.10 \pm 0.0$ & $0.07 \pm 0.0$ & $0.09 \pm 0.0$ & $0.08 \pm 0.0$ & $0.08 \pm 0.0$ & $0.09 \pm 0.0$ & 0.02 & NS & NS \\
\hline $20: 3 \omega 6$ & $0.08 \pm 0.0$ & $0.07 \pm 0.0$ & $0.08 \pm 0.0$ & $0.07 \pm 0.0$ & $0.08 \pm 0.0$ & $0.08 \pm 0.0$ & 0.02 & NS & NS \\
\hline $20: 4 \omega 3$ & $0.06 \pm 0.0$ & $0.04 \pm 0.0$ & $0.04 \pm 0.0$ & $0.03 \pm 0.0$ & $0.04 \pm 0.0$ & $0.04 \pm 0.0$ & 0.02 & NS & NS \\
\hline $20: 2 \omega 6$ & $0.06 \pm 0.0$ & $0.05 \pm 0.0$ & $0.06 \pm 0.0$ & $0.03 \pm 0.0$ & $0.04 \pm 0.0$ & $0.04 \pm 0.0$ & 0.03 & NS & NS \\
\hline $20: 0$ & $0.14 \pm 0.0$ & $0.10 \pm 0.0$ & $0.10 \pm 0.0$ & $0.10 \pm 0.0$ & $0.10 \pm 0.0$ & $0.11 \pm 0.0$ & 0.04 & NS & NS \\
\hline $22: 6 \omega 3$ & $0.01 \pm 0.0$ & $0.00 \pm 0.0$ & $0.01 \pm 0.0$ & $0.01 \pm 0.0$ & $0.00 \pm 0.0$ & $0.01 \pm 0.0$ & 0.01 & NS & NS \\
\hline $22: 4 \omega 6$ & $0.00 \pm 0.0$ & $0.00 \pm 0.0$ & $0.00 \pm 0.0$ & $0.01 \pm 0.0$ & $0.01 \pm 0.0$ & $0.01 \pm 0.0$ & 0.01 & NS & NS \\
\hline 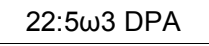 & $0.12 \pm 0.0$ & $0.11 \pm 0.0$ & $0.13 \pm 0.0$ & $0.13 \pm 0.0$ & $0.13 \pm 0.0$ & $0.15 \pm 0.0$ & 0.03 & NS & NS \\
\hline $22: 0$ & $0.06 \pm 0.0$ & $0.05 \pm 0.0$ & $0.05 \pm 0.0$ & $0.05 \pm 0.0$ & $0.05 \pm 0.0$ & $0.06 \pm 0.0$ & 0.01 & NS & NS \\
\hline
\end{tabular}

${ }^{a-c}$ Values with different superscript are significantly different: ${ }^{d} \Sigma$ tSFA is the sum of $12 \cdot 0,13 \cdot 0$, i14:0,14:0, i15:0, a15:0,15:0, i16:0, 16:0, i17:0, 17:0, i18:0, 18:0, 19:0,

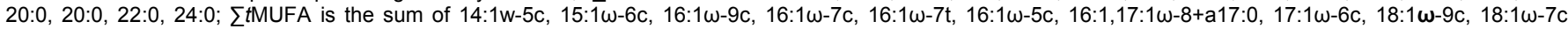
$18: 1 \omega-7 t, 18: 1 \omega-5 c, 18: 1 a, 18: 1 b, 20: 1 \omega-11 c, 20: 1 \omega-9 c, 20: 1 \omega-7 c, 20: 1 \omega-5 c, 22: 1 \omega-11 c, 22: 1 \omega-9 c, 22: 1 \omega-7 c, 24: 1 \omega-11 c, 24: 1 \omega-9 c, 24: 1 \omega-7 c ; \sum t P U F A$ is the sum

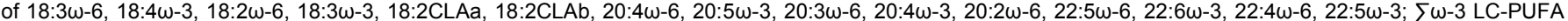

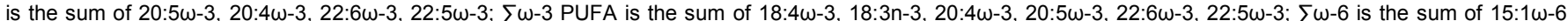
$17: 1 \omega-6,18: 2 \omega-6,18: 3 \omega-6,20: 4 \omega-6,20: 3 \omega-6,20: 2 \omega-6,22: 5 \omega-6,22: 4 \omega-6 ; t S F A=$ total saturated fatty acids; tMUFA= total monounsaturated fatty acids; tPUFA= total polyunsaturated fatty acids; $\omega-3 \mathrm{FA}=$ total omega- 3 fatty acids; $\omega-6 \mathrm{FA}=$ total omega- 6 fatty acids; $\omega-3 \mathrm{LC}-\mathrm{FA}=$ total omega- 3 long chain fatty acids; NS = no significance; ${ }^{*}=$ significant $(P<0.05) ;{ }^{* *}=$ highly significant $(P<0.01) ;{ }^{* * *}=$ very highly significant $(P<0.001)$; ${ }^{\text {e }}$ week of supplementation= weeks when cows were fed with canola oil; TRT=treatment feed, WK= Week, RMSE = root mean square error

\section{RESULTS}

\section{Fatty acid Composition of Feedstuff}

Table 2 shows that the high CDCO treatment feed contained higher proportions of 16:0, 18:1w9c, total saturated fatty acids (tSFA) and tMUFA than the control treatment. The control feed in turn, had higher

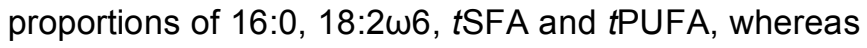
basal feed had greater proportion of 18:3w3, tPUFA and $\omega-3$ PUFA. As expected, the CDCO supplement

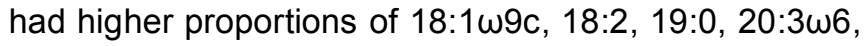

20:0 and tMUFA, but less 18:2w6, 18:3w3 and tPUFA than both the control and pasture basal diets. The pasture basal diet also had the most ALA (18:3w3) as expected.

\section{Fatty Acid Composition of Milk}

Canola oil supplementation level affected $(P<0.05)$ some of the fatty acids (Table 3 ). Fatty acid profiles of the control and treatment groups were largely similar

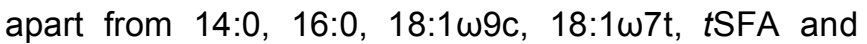
tMUFA. 


\section{Proportion of 18:1w7t in Milk}

It was evident that both level and week of CDCO supplementation were significant sources $(P<0.0002$ and $P<0.0001)$ of variation influencing $18: 1 \omega 7 t$ fatty acid. However, supplementation by week interaction had no significant effect $(P<0.3113$ : Table 3 and 4$)$. As the level of CDCO was increased, 18:1 $1 \mathrm{tt}$ fatty acid also concurrently increased in the milk. Cows in the high group produced the greatest 18:1 $1 \omega 7 \mathrm{t}$ percentage in comparison with the control group $(7.5 \pm 0.5$ vs $5.0 \pm 0.4)$, followed by the medium $(6.0 \pm 0.3$ vs $5.0 \pm 0.4)$ and low groups $(5.7 \pm 0.5$ vs $5.0 \pm 0.4)$, respectively.

\section{Proportion of 18:1w9c in Milk}

Level $(P<0.0001)$ and week $(P<0.002)$ of supplementation of cows with $\mathrm{CDCO}$ significantly affected the concentration of $18: 1 \omega 9 \mathrm{c}$ in milk. However, the interaction between treatment and week of supplementation had no significant effect $(P<0.08)$. The concentration of $18: 1 \omega 9 \mathrm{c}$ in both the high $(19.6 \pm 0.6)$ and medium (19.6 \pm 0.6$)$ treatment groups was similar, but higher than the control $(16.1 \pm 0.6)$ and low $(16.4 \pm 0.5)$ groups (Table 3 ).

\section{Proportions of tSFA and tMUFA in Milk}

As the level of CDCO increased in the diet, the level of $t S F A$ in the milk significantly decreased $(P<0.0001)$. The concentration of tMUFA was also significantly affected $(P<0.0001)$ by CDCO supplementation (Table 3). However, week of supplementation and its interaction with treatment were not significant $(P<0.1317$ and $P<1702)$ sources of variation affecting the concentration of $t$ MUFA (Table 4). The high CDCO treatment group yielded the highest proportion of tMUFAs (37.1 $\pm 1.1 \mathrm{vs} 30.2 \pm 1.0)$ compared to the other groups.

\section{Proportion of tPUFA, $\omega-3$ and $\omega-6$ in Milk}

Differences in CDCO content in the treatment groups had no significant effect on $\omega-3$ and $\omega-6$ fatty

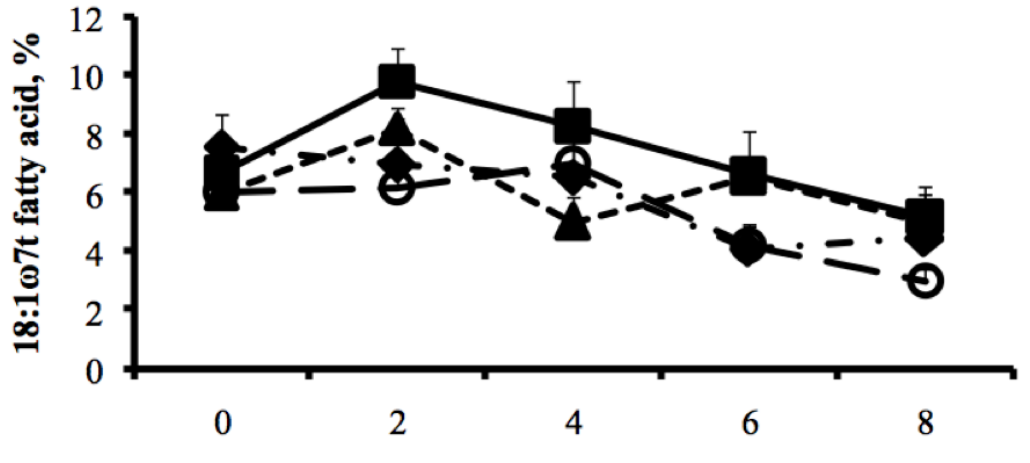

Week of supplementation

$\boldsymbol{\theta}$ Control $\rightarrow$ Low $-\boldsymbol{\Delta}$-Medium $\rightarrow$ High

Figure 1: Interaction between level and week of supplementation with $C D C O$ on the proportion of $18: 1 \omega 7 t$ in milk.

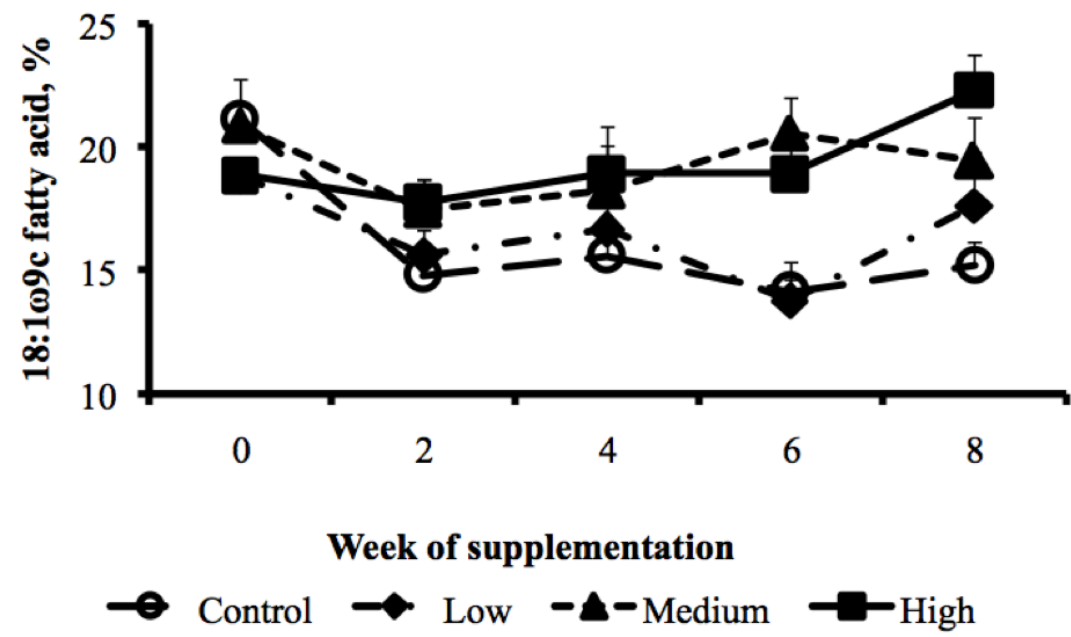

Figure 2: Interaction between level and week of supplementation with CDCO on the proportion of 18:1 w9c in milk. 
acids. However, week of supplementation was a

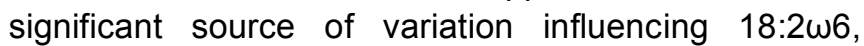

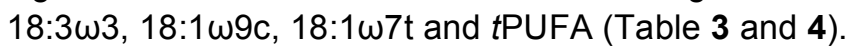

\section{Weekly Fatty Acid Composition Trends}

As the level of canola oil increased in the diet, weekly 18:1 $\omega 7 \mathrm{t}$ fatty acid also increased (Figure 1). Cows in the high oil treatment group produced the greatest $18: 1 \omega 7 \mathrm{t}$ trend rising from $6.7 \%$ to a peak of $9.8 \%$ in week two before tapering off to $5.0 \%$ at the end of the feeding trial in week eight. Milk 18:1w9c fatty acid concentration increased in the milk of cows receiving medium and high levels of CDCO in the diet (Figure 2). Cows in the control and low treatment groups consistently had the least milk $18: 1 \omega 9 \mathrm{c}$ fatty acid concentration trends throughout the trial period. Cows receiving the high and medium CDCO diets consistently produced milk with lower total tSFA percentage (Figure 3) compared to the control treatment. However, the cows in the control and low CDCO treatment groups had the greatest weekly $t$ SFA trend. Cows in the high CDCO treatment group had the greatest milk concentration of tMUFA from week two through to eight (Figure 4). tPUFA (Figure 5), $\omega-6$ (Figure 6) and $\omega-3$ (Figure 7) trends were consistently similar for all the treatment groups from weeks zero through to eight.

\section{DISCUSSION}

The observed result in the current study where proportions of $18: 1 \omega 7 \mathrm{t}$ increased with incremental levels of CDCO is in agreement with previous studies in dairy cows that utilized canola seed, extruded linseed, and oils from rapeseed, soybean and canola as dietary supplements $[25,26,27,15]$.The observed

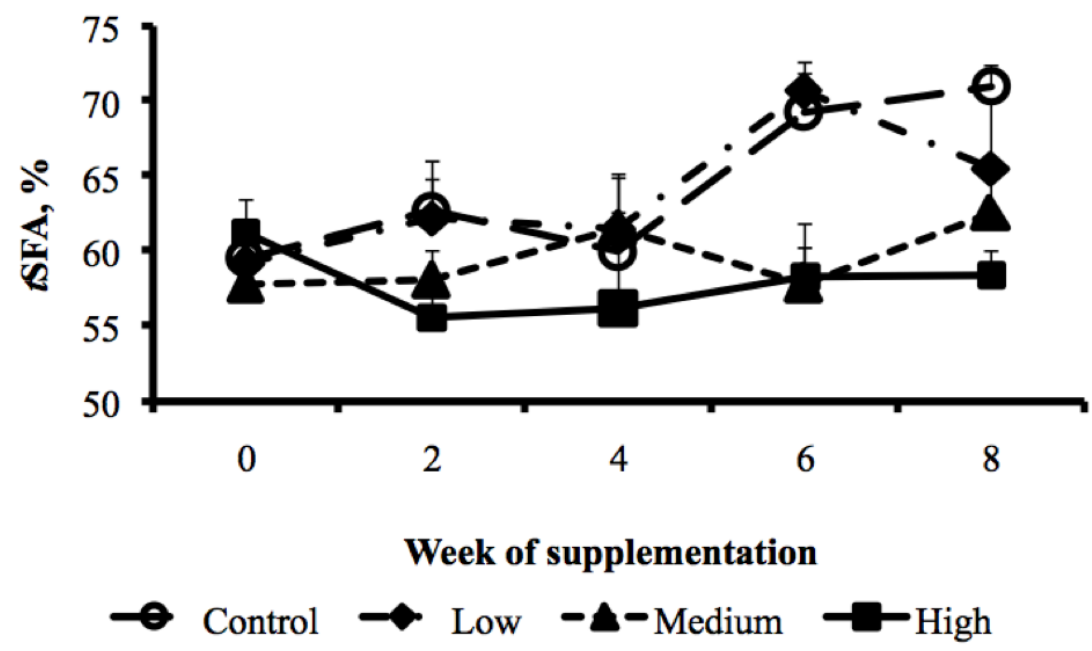

Figure 3: Interaction between level and week of supplementation with CDCO on the proportion of total saturated fatty acid $($ tSFA) in milk.

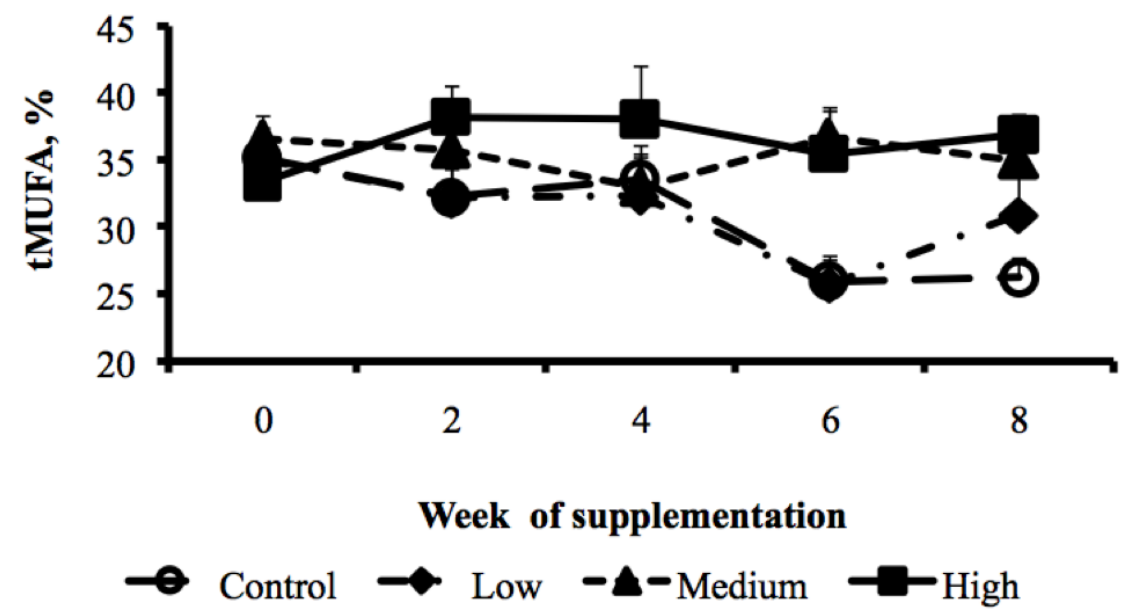

Figure 4: Influence of level and week of CDCO supplementation on the proportion of total monounsaturated fatty acid ( $t M U F A)$ in milk. 


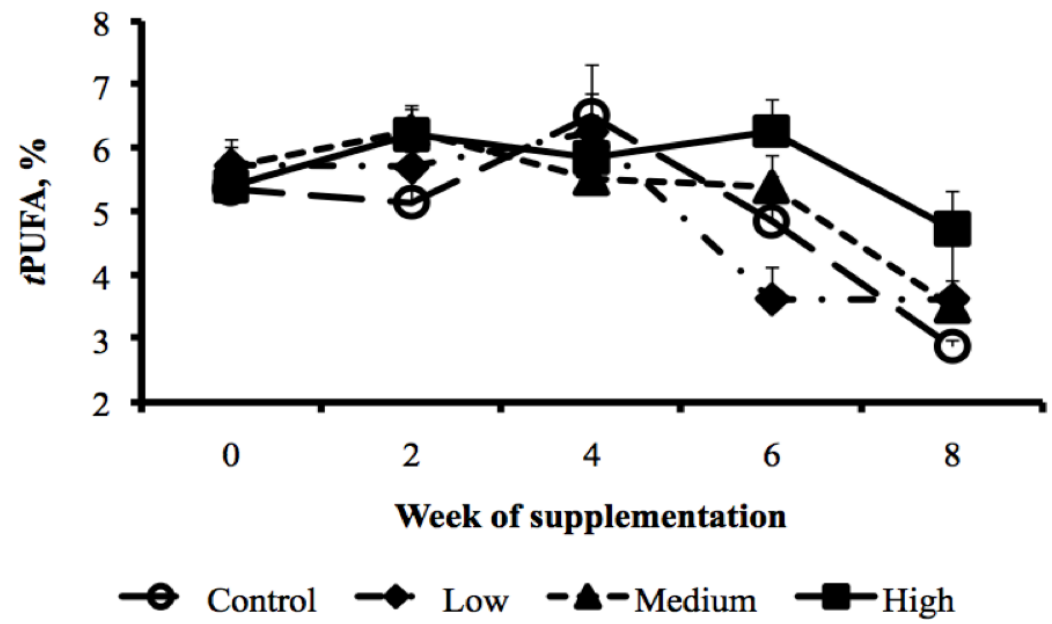

Figure 5: Influence of level and week of supplementation with CDCO on the proportion of total polyunsaturated fatty acid (tPUFA) in milk.

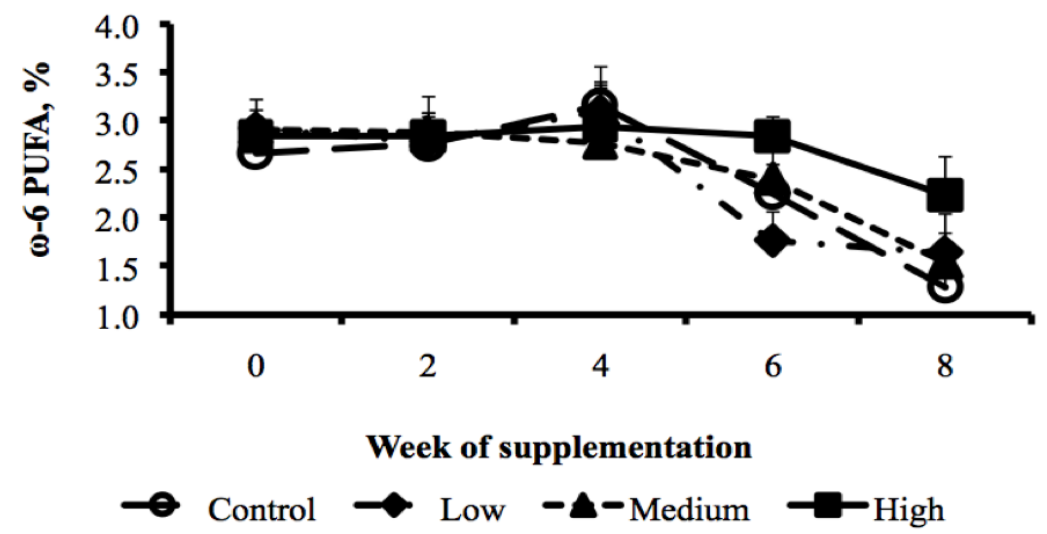

Figure 6: Influence of level and week of supplementation with CDCO on the proportion of $\omega-6$ fatty acids in milk.

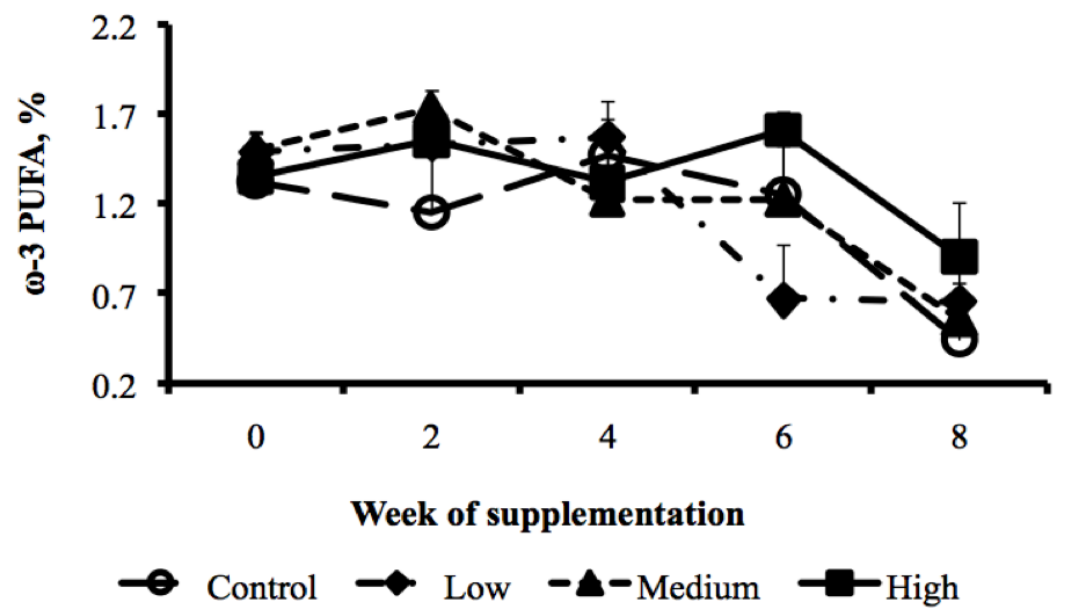

Figure 7: Interaction between level and week of supplementation with CDCO on the proportion of $\omega$-3 fatty acids in milk.

differences in the proportions of $18: 1 \omega 7 \mathrm{t}$ across treatment groups was possibly due to differences in the proportion of $18: 1 \omega 9 \mathrm{c}$ between the diets. This is in tandem with the findings of AbuGhazaleh et al. [28], that enhancing trans-18:1 fatty acid in milk is possible if a high concentration of dietary $18: 1 \omega 9 c$ is available. In this current study, there were high 18:1w9c proportions in the experimental diets that led to the observed variations in $18: 1 \omega 7 \mathrm{t}$ in the milk. 
Supplementation of lactating cows with CDCO had a positive impact on the proportion of $18: 1 \omega 9 \mathrm{c}$ in agreement with previous studies $[2,14,29]$. Increased concentration of $18: 1 \omega 9 \mathrm{c}$ is usually associated with rumen biohydrogenation of 18:0, an essential precursor for the synthesis of $18: 1 \omega 9 c[3,14,30,31,32]$. It has also been reported that the majority of $18: 1 \omega 9 \mathrm{c}$ fatty acid found in milk is as a result of desaturation of 18:0 fatty acids in the mammary gland [33]. Previous studies have also indicated that using rich vegetable sources of oleic acid is essential for enhancing the concentration of $18: 1 \omega 9 \mathrm{c}$ in milk fat $[34,35,36]$.

The decrease in the concentration of tSFA is consistent with the known effect of canola/rapeseed on milk SFA profile $[2,37]$. Production of acetic, propionic, and butyric acids by rumen microbes as substrates for energy synthesis have been associated with the production of short and medium branched-chain SFA $[38,39]$. Therefore, the variation of $t S F A$ between groups suggests that addition of CDCO in the diet of lactating cows possibly affected the activities of rumen microbes leading to milk fat depression.

The proportion of milk $t$ MUFA was high for cows in the high and medium $\mathrm{CDCO}$ treatment groups. This enhanced $t$ MUFA is largely due to the elevated $18: 1 \omega 9 \mathrm{c}$ in the diet [14], which aligns with results of previous studies $[2,27]$. The increasing level of $t$ MUFA at the expense of $t S F A$ observed in the current study could be beneficial to human health [40]. No significant treatment differences were observed in the proportions of $t$ PUFAs, $\omega-3$ and $\omega-6$ fatty acids, while $18: 1 \omega 7 t$ and $18: 1 \omega 9 c$ were significantly increased by the duration of CDCO supplementation. This lends credence to the report of Martínez-Marín et al., [41] who demonstrated that in goats, time is an important factor in the modification of milk fatty acids. Therefore, the duration of supplementation may be just as crucial as the dietary composition in modifying milk fatty acid composition in grazing cows.

Therefore, the current results seem to suggest that to enhance the proportions of $18: 1 \omega 9 \mathrm{c}, 18: 1 \omega 7 \mathrm{t}$ and tMUFA at the expense of $t$ SFA, primiparous HolsteinFriesian dairy cows grazing pastures need to be supplemented with CDCO at levels greater than $35 \mathrm{ml}$ $/ \mathrm{Kg}$ DM for a duration of eight weeks and tMUFA will continue to rise linearly at the expense of $t S F A$ (Figures 3 and 4). Our current study also did agree with the findings of Ferlay et al., [27] who found that feeding linseed to dairy cows increased the proportion of MUFA at the expense of SFA.

\section{CONCLUSIONS}

The observed increases in the proportions of $18: 1 \omega 9 \mathrm{c}, 18: 1 \omega 7 \mathrm{t}$ and $t$ MUFA at the expense of $t S F A$, suggest that the supplementation of grazing primiparous Holstein-Friesian cows with CDCO can potentially improve milk quality and enhance its beneficial healthy fatty acid profile without any negative impact on the animals or milk taste. Therefore, the tested hypothesis that incremental supplementation of grazing primiparous Holstein-Friesian cows with CDCO will alter milk fatty acid composition towards increased total monounsaturates holds true and should be accepted.

\section{ACKNOWLEGEMENTS}

This study was supported with research grants from the University of Tasmania Graduate Research Scholarship and Postgraduate Top-up scholarships from the Tasmanian Institute of Agriculture's Dairy Research Centre. We also acknowledge the field advisory and supervisory roles of Mark Freeman and Peter Lane and are also grateful for the collaborative research support from CopRice Feeds, Cobden, Victoria and Peter Nish of TasHerd Pty Limited, Hadspen, Tasmania, for the pelleted feeds and milk composition analysis, respectively.

\section{REFERENCES}

[1] Dairy Australia [Situation and Outlook]; 2010-2014 [updated 2014 January 1; cited 2014 March 6]: Available from: http://www.dairyaustralia.com.au/

[2] Glasser F, Ferlay A, Chilliard Y. Oilseed lipid supplements and fatty acid composition of cow milk: a meta-analysis. J Dairy Sci 2008; 91: 4687-703.

http://dx.doi.org/10.3168/jds.2008-0987

[3] Hristov A, Domitrovich C, Wachter A, et al. Effect of replacing solvent-extracted canola meal with high-oil traditional canola, high-oleic acid canola, or high-erucic acid rapeseed meals on rumen fermentation, digestibility, milk production, and milk fatty acid composition in lactating dairy cows. J Dairy Sci 2011; 94: 4057-74.

http://dx.doi.org/10.3168/ids.2011-4283

[4] Palmquist DL, Beaulieu AD, Barbano DM. Feed and animal factors influencing milk fat composition. J Dairy Sci 1993; 76: 1753-71.

[5] Dewhurst RJ, Shingfield KJM, Lee RF, Scollan ND. Increasing the concentrations of beneficial polyunsaturated fatty acids in milk produced by dairy cows in high-forage systems. Anim Feed Sci Technol 2006; 131: 168-206.

[6] Chilliard Y, Glasser F, Ferlay A, Bernard L, Rouel J, Doreau $M$. Diet, rumen biohydrogenation and nutritional quality of cow and goat milk fat. Eur J Lipid Sci Tech 2007; 109: 82855 .

http://dx.doi.org/10.1002/ejlt.200700080 
[7] Shingfield K, Bernard L, Leroux C, Chilliard Y. Role of trans fatty acids in the nutritional regulation of mammary lipogenesis in ruminants. Animal 2010; 4: 1140-66. http://dx.doi.org/10.1017/S1751731110000510

[8] Field CJ, Blewett $\mathrm{HH}$, Proctor S, Vine D. Human health benefits of vaccenic acid. Appl Physiol Nutr Me 2009; 34: 979-91.

http://dx.doi.org/10.1139/H09-079

[9] Simopoulos AP. The importance of the $n-6 / n-3$ fatty acid ratio in cardiovascular disease and other chronic diseases. Exp Biol Med 2008; 233: 674-88. http://dx.doi.org/10.3181/0711-MR-311

[10] Chardigny JM, Destaillats F, Malpuech-Brugère $C$, et al. Do trans fatty acids from industrially produced sources and from natural sources have the same effect on cardiovascular disease risk factors in healthy subjects? Results of the trans Fatty Acids Collaboration (TRANSFACT) study. Am J Clin Nutr 2008; 87: 558-66.

[11] Givens D. Milk and meat in our diet: good or bad for health? Animal 2010; 4: 1941-52. http://dx.doi.org/10.1017/S1751731110001503

[12] Ashes J, Vincent-Welch PS, Gulati S, Scott T, Brown G, Blakeley S. Manipulation of the fatty acid composition of milk by feeding protected canola seeds. J Dairy Sci 1992; 75: 1090-96.

http://dx.doi.org/10.3168/jds.S0022-0302(92)77853-9

[13] Khorasani, G, Robinson P, De Boer G, Kennelly J. Influence of canola fat on yield, fat percentage, fatty acid profile, and nitrogen fractions in Holstein milk. J Dairy Sci 1991; 74: 1904-11.

http://dx.doi.org/10.3168/jds.S0022-0302(91)78356-2

[14] Delbecchi L, Ahnadi C, Kennelly J, Lacasse P. Milk fatty acid composition and mammary lipid metabolism in Holstein cows fed protected or unprotected canola seeds. J Dairy Sci 2001; 84:1375-81.

http://dx.doi.org/10.3168/jds.S0022-0302(01)70168-3

[15] Jacobs AAA, van Baal J, Smits MA, et al. Effects of feeding rapeseed oil, soybean oil, or linseed oil on stearoyl-CoA desaturase expression in the mammary gland of dairy cows. J Dairy Sci 2011; 94: 874-87.

http://dx.doi.org/10.3168/jds.2010-3511

[16] Stockdale C. Body condition at calving and the performance of dairy cows in early lactation under Australian conditions: a review. Anim Prod Sci 2001; 41: 823-39. http://dx.doi.org/10.1071/EA01023

[17] DPI. The Condition Magician. Body condition scoring in dairy herds. Seasonal /split and year round calving. $2^{\text {nd }}$ ed. Department of Primary Industry: Victoria 2003.

[18] Schroeder G, Gagliostro G, Bargo F, Delahoy J, Muller L. Effects of fat supplementation on milk production and composition by dairy cows on pasture: a review. Livest Prod Sci 2004; 86: 1-18.

http://dx.doi.org/10.1016/S0301-6226(03)00118-0

[19] VanSoest PV, Robertson J, Lewis B. Methods for dietary fiber, neutral detergent fiber, and non-starch polysaccharides in relation to animal nutrition. J Dairy Sci 1991; 74:3583-97. http://dx.doi.org/10.3168/jds.S0022-0302(91)78551-2

[20] Del Galdo I, Oechel WC, Francesca-Cotrufo M. Effects of past, present and future atmospheric $\mathrm{CO}_{2}$ concentrations on soil organic matter dynamics in a chaparral ecosystem. Soil Biol Biochem 2006; 38: 3235-44.

http://dx.doi.org/10.1016/j.soilbio.2006.04.012

[21] Weiss WP. Predicting energy values of feeds. J Dairy Sci 1993; 76: 1802-11.

http://dx.doi.org/10.3168/jds.S0022-0302(93)77512-8

[22] Kroger M. Milk sample preservation. J Dairy Sci 1985; 68: 783-87.

http://dx.doi.org/10.3168/jds.S0022-0302(85)80889-4
[23] Codabaccus BM, Carter CG, Bridle AR, Nichols PD. The "n-3 LC-PUFA sparing effect" of modified dietary n-3 LC-PUFA content and DHA to EPA ratio in Atlantic salmon smolt. Aquaculture 2012; 356-357: 135-140.

[24] SAS. Statistical Analysis System. SAS Institute, Cary, NC, USA 2009; v9.2

[25] Kliem K, Shingfield K, Humphries D, Givens D. Effect of replacing calcium salts of palm oil distillate with incremental amounts of conventional or high oleic acid milled rapeseed on milk fatty acid composition in cows fed maize silagebased diets. Animal 2011; 5: 1311. http://dx.doi.org/10.1017/S1751731111000310

[26] Chichlowski MW, Schroeder JW, Park CS, Keller WL, Schimek DE. Altering the fatty acids in milk fat by including canola seed in dairy cattle diets. J Dairy Sci 2005; 88: 308494.

http://dx.doi.org/10.3168/jds.S0022-0302(05)72990-8

[27] Ferlay A, Doreau M, Martin C, Chilliard Y. Effects of incremental amounts of extruded linseed on the milk fatty acid composition of dairy cows receiving hay or corn silage. J Dairy Sci 2013; 96: 6577-95.

http://dx.doi.org/10.3168/jds.2013-6562

[28] AbuGhazaleh A, Riley M, Thies E, Jenkins T. Dilution rate and $\mathrm{pH}$ effects on the conversion of oleic acid to trans-18:1 positional isomers in continuous culture. J Dairy Sci 2005; 88: 4334-41.

http://dx.doi.org/10.3168/jds.S0022-0302(05)73120-9

[29] DePeters E, German J, Taylor S, Essex S, Perez-Monti H. Fatty acid and triglyceride composition of milk fat from lactating Holstein cows in response to supplemental canola oil. J Dairy Sci 2001; 84: 929-36. http://dx.doi.org/10.3168/jds.S0022-0302(01)74550-X

[30] Banks W. Opportunities for varying the composition of cows' milk. Int J Dairy Tech 1987; 40: 96-9. http://dx.doi.org/10.1111/j.1471-0307.1987.tb02412.x

[31] Chang JH, Lunt DK, Smith SB. Fatty-acid composition and fatty acid elongase and stearoyl-CoA desaturase activities in tissues of steers fed high oleate sunflower seed. J Nutr 1992; 122: 2074-80.

[32] Ntambi JM. Regulation of stearoyl-CoA desaturase by PUFA and cholesterol. J Lipid Res 1999; 40: 1549-58.

[33] Enjalbert F, Nicot MC, Bayourthe C, Moncoulon R. Duodenal infusions of palmitic, stearic or oleic acids differently affect mammary gland metabolism of fatty acids in lactating dairy cows. J Nutr 1998; 128: 1525-32.

[34] Bernard L, Rouel J, Leroux C, et al. Mammary lipid metabolism and milk fatty acid secretion in Alpine goats fed vegetable lipids. J Dairy Sci 2005; 88: 1478-89. http://dx.doi.org/10.3168/jds.S0022-0302(05)72816-2

[35] Bodas R, Manso T, Mantecón AR, Juárez M, De la Fuente MA, Gómez-Cortés P. Comparison of the fatty acid profiles in cheeses from ewes fed diets supplemented with different plant oils. J Agr Food Chem 2010; 58: 10493-502. http://dx.doi.org/10.1021/jf101760u

[36] Gómez-Cortés, Frutos P, Mantecon A, Juárez M, De La Fuente M, Hervas G. Addition of olive oil to dairy ewe diets: Effect on milk fatty acid profile and animal performance. J Dairy Sci 2008; 91: 3119-27.

\section{http://dx.doi.org/10.3168/jds.2007-0954}

[37] Aldrich C, Merchen N, Drackley J, Fahey G, Berger L. The effects of chemical treatment of whole canola seed on intake, nutrient digestibilities, milk production, and milk fatty acids of Holstein cows. J Anim Sci 1997; 75: 512-21.

[38] Bernard L, Shingfield KJ, Rouel J, Ferlay A, Chilliard Y. Effect of plant oils in the diet on performance and milk fatty acid composition in goats fed diets based on grass hay or maize silage. Brit J Nutr 2009; 101: 213.

http://dx.doi.org/10.1017/S0007114508006533 
[39] Vlaeminck B, Fievez V, Tamminga S, et al. Milk odd-and branched-chain fatty acids in relation to the rumen fermentation pattern. J Dairy Sci 2006; 89: 3954-64. http://dx.doi.org/10.3168/jds.S0022-0302(06)72437-7

[40] Williams CM. Dietary fatty acids and human health: a review. Ann Zootech 2000; 49: 165-80.

http://dx.doi.org/10.1051/animres:2000116
[41] Martínez-Marín AL, Gómez-Cortés P, Gómez Castro G, et al. Time-dependent variations in milk fatty acid content of goats fed 3 different plant oils. J Dairy Sci 2013; 96: 3238-46. http://dx.doi.org/10.3168/jds.2012-6313

Received on 04-04-2014

Accepted on 18-05-2014

Published on 15-06-2014

DOI: http://dx.doi.org/10.6000/1929-5634.2014.03.02.4

(C) 2014 Otto et al.; Licensee Lifescience Global.

This is an open access article licensed under the terms of the Creative Commons Attribution Non-Commercial License (http://creativecommons.org/licenses/by-nc/3.0/) which permits unrestricted, non-commercial use, distribution and reproduction in any medium, provided the work is properly cited. 